\title{
The relationship between pupil size and recognition threshold '
}

\author{
L. D. HUTT, MEMPIIS STATE UNIHERSITY \\ J. P. ANDERSON, UNIVERSITY OF ARKANSAS
}

Words representing a broad range of (motional connotation (taboo, pleasant, and unpleasant) were lrescented both pupitometrically and tachistoscopically to college students. As predicted, a statistically significant negative correlation was obtained between pupil diamcter and recogmition throsholds of the words. The results were interpreted as offering tentative support of the notion that the plipil response to emotional stimuli is the mechanism of perceptual defense and rigilance.

In an earlier article in this journal (Hutt \& Anderson, 1967), the authors suggested that a plausible mechanism of perceptual defense and vigilance is the autonomic pupil response to emotional stimuli. Investigations of the pupil response (Hess, 1965; Hess \& Polt, 1960) have found that, in general, the pupil dilates to pleasant stimuli and contracts to unpleasant stimuli. It seems plausible to suppose that taboo words used in perceptual defense studies initiate pupil contraction, thus admitting less light into the eye and raising recognition threshold, i.e., perceptual defense. Conversely, pleasant stimuli initiate pupil dilation, thus admitting more light into the eye and perhaps lowering recognition threshold, i.e., perceptual vigilance.

Several testable hypotheses are suggested by this general notion, perhaps the most fundamental of which is that of a negative correlation between pupil size while viewing a particular stimulus and the recognition threshold of that stimulus. A test of that hypothesis was the purpose of this experiment.

Method

In an effort to produce considerable variation in pupil size and recognition threshold, words representing a wide range of emotional connotation-taboo, pleasant, unpleasant-were used as stimuli in the experiment. With each emotional word was paired a neutral word matched with it in terms of ThorndikeLorge (1944) frequency and, insofar as possible, in terms of structural characteristics. Pupil size while viewing the neutral word and recognition threshold of the neutral word served as the standard or baseline with which pupil size and recognition threshold of the paired emotional word were compared. The emotional-neutral pairs are presented in Table 1 below. The number in parentheses refers to the frequency rating of the pair.

Forty students, 20 males and 20 females, drawn from introductory psychology classes, served as Ss. In the first part of the experiment $S$ viewed the words in a pupilometer patterned as closely as possible after that used by Hess and issociates. Each word was presented well above threshold for a period of $10 \mathrm{sec}$, during which time the camera filmed the left eye at a rate of 2 frames per sec. A different random order of word presentation was used for each $S$ with the restriction that the neutral member of the word pair always preceded the emotional member of the pair.

Following pupilometric presentation of the words the same words were presented tachistoscopically. An ascending method of limits, with four ascending series, was begun at an exposure interval of $.01 \mathrm{sec}$ and increased to $.02, .04, .10, .50$, and $1.00 \mathrm{sec}$. The series was terminated at the exposure interval yielding $100 \%$ recognition. A different random order of stimulus presentation was used at each exposure interval and for each of the four ascending series.

The pupilometric technique resulted in 20 frames (pictures) of the pupil per word per S. Each frame of the pupil image, enlarged, was measured manually with a set of dividers. This resulted in 20 measures of pupil diameter per word per $S$, which were averaged to yield a mean pupil diameter for each of the 12 words for each $\mathrm{S}$. Mean pupil diameter for the neutral member of a pair was subtracted from mean pupil diameter for the emotional member of the pair, yielding a pupil size Difference Score for each word pair for each S. An analogous Difference Score for recognition threshold was obtained by subtracting mean recognition threshold for the neutral member of the word pair from mean recognition threshold of the emotional member of the pair. Results

Pearson $r$ was used in describing the data and in the test of significance. Specifically, the values correlated were Difference Scores for pupil size with Difference Scores for recognition threshold. The obtained value of $r$ with $\mathrm{df}=239$ was -.189 , significantly different from $r=0$ at the .005 level. The magnitude of the correlation, though significant, was considerably less than had been expected, and less than would be desired. It is probable that since the words used were selected intuitively, some of the words were not particularly emotionally arousing for some Ss, and it is also probable that a good deal of error was introduced into the data by the pupil measurement

Table 1. Emotional-Neutral Word Pairs

Taboo Unpleasant Pleasant

QUEER (3b) OUART SLIME (3) SLOTH SIRLOIN (11) SECLUDE WHORE (7) WHINE VOMIT (8) VAUNT SOFT (la) SING 
technique. Both of these factors undoubtedly contributed to depressing the magnitude of the correlation. If these factors are controlled, it seems highly probable that the size of the correlation will be found to increase substantially.

\section{Discussion}

These data lend unequivocal support to the hypothesis tested; i.e., under the conditions of this experiment pupil size and recognition threshold were found to be significantly and negatively related. Even though these findings indicate clearly a significant negative correlation between pupil size and recognition threshold, which is precisely the relationship one would expect if the autonomic pupil response is the basis of perceptual defense and vigilance, these data must be interpreted with caution. The data do not indicate that pupil size causes variations in recognition threshold. The findings do, however, make a causal relationship more plausible and suggest that the relation between pupil size and recognition threshold warrants further investigation.

A causal interpretation of the relation between pupil size and recognition threshold must await answers to two questions: (1) Does the pupil response occur prior to recognition of the stimulus, i.e., is the latency of the pupil response less than the latency (duration recognition threshold) of recognition? and (2) Does variation in pupil size cause variation in recognition threshold?

In order to be less than the latency of recognition the latency of the pupil response must be on the order of a few hundredths of a second. To the authors' knowledge, no precise determinations of pupil response latency have been attempted. It has been shown, however, that the pupil has changed detectably in size .10 sec following stimulus presentation (Reeves, 1918), the smallest latency detectable with the technique used by Reeves. A more precise determination of pupil response latency (to the nearest $.01 \mathrm{sec}$ ) is now being made by the senior author. With regard to the question of whether variations in pupil size cause variations in recognition threshold, experiments are now being conducted to determine if pupil size manipulated by means of an artificial pupil produces the expected variations in duration recognition thresholds of visually presented stimuli.

\section{References}

HESS, E. H. Attitude and pupil size. Scient. American, 1965, 212, 46-54.

HESS, E. H., \& POLT, J. Pupil size as related to interest value of visual stimuli. Science, 1960, 349-350.

HUTT, L. D., \& ANDERSON, J. P. Perceptual defense and vigilance: Prediction from the Byrne Scale of Repression-Sensitization. Psychon. Sci. 1967, Nov. 15 , in press.

REEVES, P. Rate of pupillary dilation and contraction. Psychol. Rev., $1918,25,330-340$.

THORNDIKE, E. L., \& LORGE, I. The Teacher's Word Book of 30,000 Words. Bureau of Publications, Teachers College, Columbia University, 1944, New York.

Note

1. The authors wish to express their appreciation for the assistance of Dr. Hardy Wilcoxon, Peabody College, and Drs. W. W. Kimbrough and W. J. Richards, University of Arkansas, for their invaluable assistance in the planning of the experiment reported here. We wish also to thank Graduate Dean Virgil Adkisson for his assistance in obtaining financial support for the project. 